\title{
Measuring the Service Quality of Community Development Associations Using Importance-Performance Analysis
}

\author{
Han-Chen Huang \\ Department of Leisure Management, Yu Da University, Taiwan
}

\begin{abstract}
A community development association (CDA) has been established in every village or neighborhood in Taiwan. The purpose of CDAs is to enhance residents' living quality. The services provided by CDAs should fulfill and even exceed residents' expectations, and the performance of these services should be approved by the residents. When their expectations are not met, residents become dissatisfied with the services provided and eventually lose their community identity. Thus, based on a SERVQUAL questionnaire developed in this study, we used the importance-performance analysis (IPA) method to investigate the service quality of CDAs. The findings of this study can be used to improve and enhance the service quality of CDAs.
\end{abstract}

Keywords - Community Development Association, Service, Performance, Important-Performance Analysis

\section{INTRODUCTION}

The services provided by community development associations (CDAs) include tangible activities, facilities, and intangible concern, with the purpose of enhancing residents' quality of life [1-4]. However, in the course of serving residents, the cognitive gap between CDAs and the residents, or the ineffective execution of services by CDAs causes dissatisfaction and opposition among the residents [4-6]. Thus, the development of methods for improving and enhancing service quality to achieve residents' approval is crucial for CDAs.

We modified the SERVQUAL questionnaire proposed by Parasuraman, Zeithmal, and Berry [7-10] to produce a scale suitable for measuring the service attributes of CDAs (Table 1). Subsequently, we conducted importance-performance analysis (IPA) [11-13] to measure service quality [14-16]. The results of this study can be used to improve and enhance the service quality of CDAs.

Table 1: The questionnaire structure

\begin{tabular}{|c|c|c|}
\hline Dimension & Items & \\
\hline Empathy & $\begin{array}{l}1 . \\
2 . \\
3 . \\
4 .\end{array}$ & $\begin{array}{l}\text { The association values resident welfare } \\
\text { The association shows concern for low-income households and offers subsidies } \\
\text { Activities arranged by the association meet resident demands } \\
\text { Activities arranged by the association enhance emotional communication among residents }\end{array}$ \\
\hline Responsiveness & $\begin{array}{l}6 . \\
7 . \\
8 .\end{array}$ & $\begin{array}{l}\text { The community has various means of announcing messages (e.g., bulletin boards, websites, } \\
\text { and broadcasts) } \\
\text { The association positively assists residents in need } \\
\text { Association staff and volunteers gladly assist residents } \\
\text { Association staff and volunteers maintain polite attitudes when providing services to residents }\end{array}$ \\
\hline Tangibility & $\begin{array}{c}10 . \\
11 . \\
12 . \\
13 .\end{array}$ & $\begin{array}{l}\text { The environmental protection volunteers periodically clean and sanitize the community area, } \\
\text { providing a comfortable, pleasant, and hygienic living environment } \\
\text { Neighborhood watch members patrol the community area at night, ensuring a peaceful and } \\
\text { safe living environment } \\
\text { The association arranges lectures, lessons, and trips to enrich residents' cultural and leisure } \\
\text { lifestyles } \\
\text { The association provides dance lessons to encourage women to get involved in community } \\
\text { activities } \\
\text { The association organizes morning gatherings to promote national exercise and enhance } \\
\text { health }\end{array}$ \\
\hline Reliability & $\begin{array}{l}14 . \\
15 . \\
16 .\end{array}$ & $\begin{array}{l}\text { The communities leisure facilities satisfy residents' demands } \\
\text { The community has installed a monitoring system to further protect residents' assets } \\
\text { The community has installed a broadcast system to instantly broadcast various messages }\end{array}$ \\
\hline Assurance & $\begin{array}{l}17 . \\
18 . \\
19 . \\
20 .\end{array}$ & $\begin{array}{l}\text { The association staff demonstrate professionalism } \\
\text { The image and reputation of the association is excellent and credible to the residents } \\
\text { The association integrates private companies, societies, and government resources to promote } \\
\text { community work } \\
\text { In your opinion, how important is the CDA for the promotion of community work? }\end{array}$ \\
\hline
\end{tabular}




\section{IMPORTANCE-PERFORMANCE ANALYSIS}

IPA is a measurement method that incorporates consumer-perceived importance and performance, and subsequently prioritizes the related attributes of services in sequential order [17, 18]. IPA is an effective method for improving service quality, and is widely applied in a number of different fields. The procedural steps of IPA are as follows [19-23]:

- List the various attributes for leisure-based activities and services, and subsequently develop a questionnaire.

- The participants evaluate and rate the listed attributes according to "Importance" and "Performance".

- Using "Importance" as the horizontal axis and "Performance" as the vertical axis, plot the various attributes into a $2 \mathrm{D}$ matrix.

- Using the midpoint or average value as the point of separation, divide the matrix into four quadrants (Figure 1).

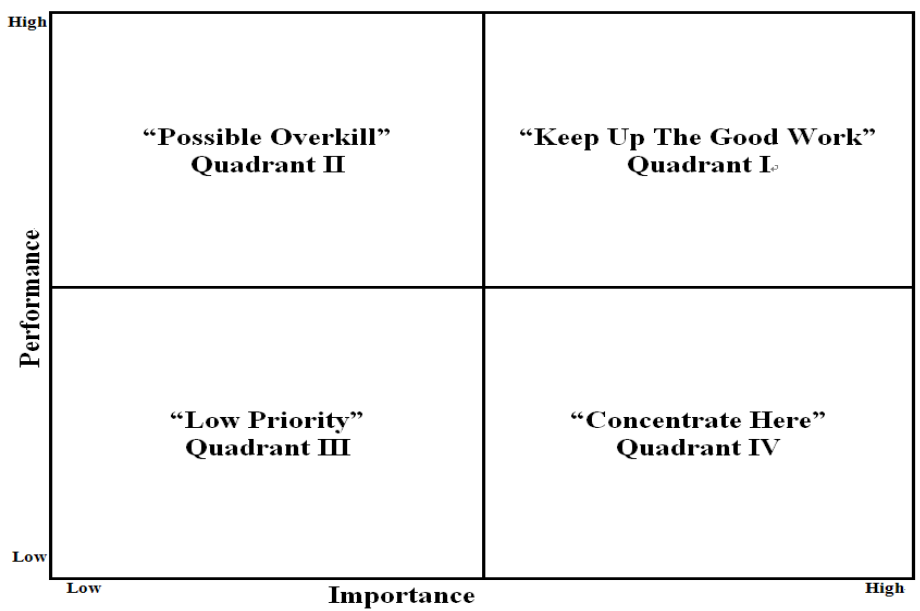

Figure 1. Importance-Performance Analysis

Deng et al. [24]: "Attributes located in Quadrant I (both performance and importance are high) indicate opportunities for achieving or maintaining competitive advantage and are major strengths. The management scheme for this quadrant is 'keep up the good work'. Attributes located in Quadrant II (performance is high and importance is low) indicate that business resources committed to these attributes would be overkill and should be deployed elsewhere. These attributes are minor strengths. The management scheme for this quadrant is 'possible overkill'. Attributes in Quadrant III (performance and importance are low) are minor weaknesses and do not require additional effort. The management scheme for this quadrant is 'low priority'. Attributes located in Quadrant IV (performance is low and importance is high) require immediate attention for improvement and are major weaknesses. The management scheme for this quadrant is 'concentrate here'. The inability to identify these attributes can threaten a firm's place in the market and typically results in low consumer satisfaction."

\section{INVESTIGATION RESULTS AND ANALYSIS}

A questionnaire survey was employed to measure the service quality of CDAs. The questionnaire was divided into "importance" and "satisfaction," and a 5-point Likert scale was used for the scaling system. A CDA in New Taipei City was selected as the research subject. A total of 455 questionnaires were distributed, and 255 valid questionnaires were recovered. Based on the reliability analysis results, Cronbach's $\alpha$ values for the questionnaire ranged between 0.8003 and 0.8913 (Table 2). This suggests that the scoring system adopted for scaling possessed a high level of reliability.

Table 2. Reliability analysis results

\begin{tabular}{ccc}
\hline Dimension & \multicolumn{3}{c}{ Cronbach's $\alpha$} & Satisfaction \\
\hline Empathy & Importance & 0.8913 \\
Responsiveness & 0.8295 & 0.8439 \\
Tangibility & 0.8425 & 0.8675 \\
Reliability & 0.8337 & 0.8003 \\
Assurance & 0.8562 & 0.8855 \\
\hline
\end{tabular}


The "Importance" and "Satisfaction" results for the various items are tabulated in Table 3, and the IPA results are shown in Figs. 2 and 3. As shown in Figure 2, using a score of 3 in the 5-point Likert scale system as the point of separation for the quadrants, 20 items were distributed in Quadrant I. This suggests that residents exhibited high perceptions regarding the importance and performance of the services provided by the CDA.

Table 3. Investigatory results for importance and satisfaction

\begin{tabular}{ccccc}
\hline \multirow{2}{*}{ Item number* } & Mean & \multicolumn{2}{c}{ Standard Deviation } \\
& Importance & Satisfaction & Importance & Satisfaction \\
\hline 1 & 3.79 & 3.40 & 0.61 & 0.55 \\
3 & 3.71 & 3.68 & 0.54 & 0.51 \\
4 & 3.61 & 3.41 & 0.44 & 0.45 \\
5 & 3.68 & 3.51 & 0.61 & 0.57 \\
6 & 3.79 & 3.55 & 0.64 & 0.67 \\
7 & 3.91 & 3.32 & 0.78 & 0.54 \\
8 & 3.56 & 3.47 & 0.70 & 0.43 \\
9 & 3.71 & 3.59 & 0.69 & 0.53 \\
10 & 3.84 & 3.75 & 0.61 & 0.52 \\
11 & 4.02 & 3.75 & 0.55 & 0.68 \\
12 & 3.76 & 3.68 & 0.44 & 0.70 \\
13 & 3.35 & 3.39 & 0.45 & 0.69 \\
14 & 3.46 & 3.57 & 0.51 & 0.63 \\
15 & 3.72 & 3.67 & 0.46 & 0.53 \\
16 & 3.48 & 3.66 & 0.43 & 0.46 \\
17 & 4.31 & 3.58 & 0.41 & 0.79 \\
18 & 4.35 & 3.56 & 0.52 & 0.70 \\
19 & 3.75 & 3.44 & 0.40 & 0.41 \\
20 & 3.65 & 3.49 & 0.63 & 0.65 \\
\hline For an explanation of the codes, please refer to Table 1. & 3.65 & 0.75 & \\
\hline
\end{tabular}

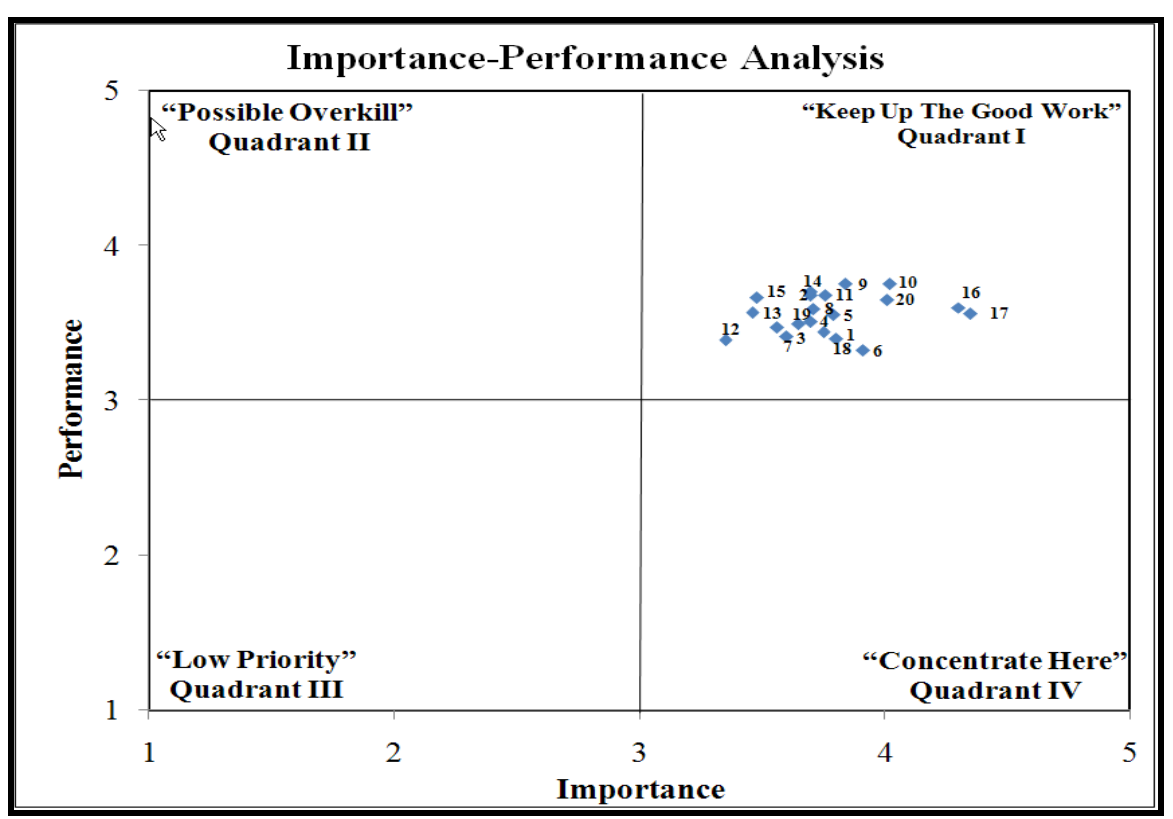

Figure 2. IPA results (using a score of 3 as the midpoint) 
To further understand the service insufficiencies of the CDA, we used average values as the point of separation to obtain more detailed IPA results (Figure 3).

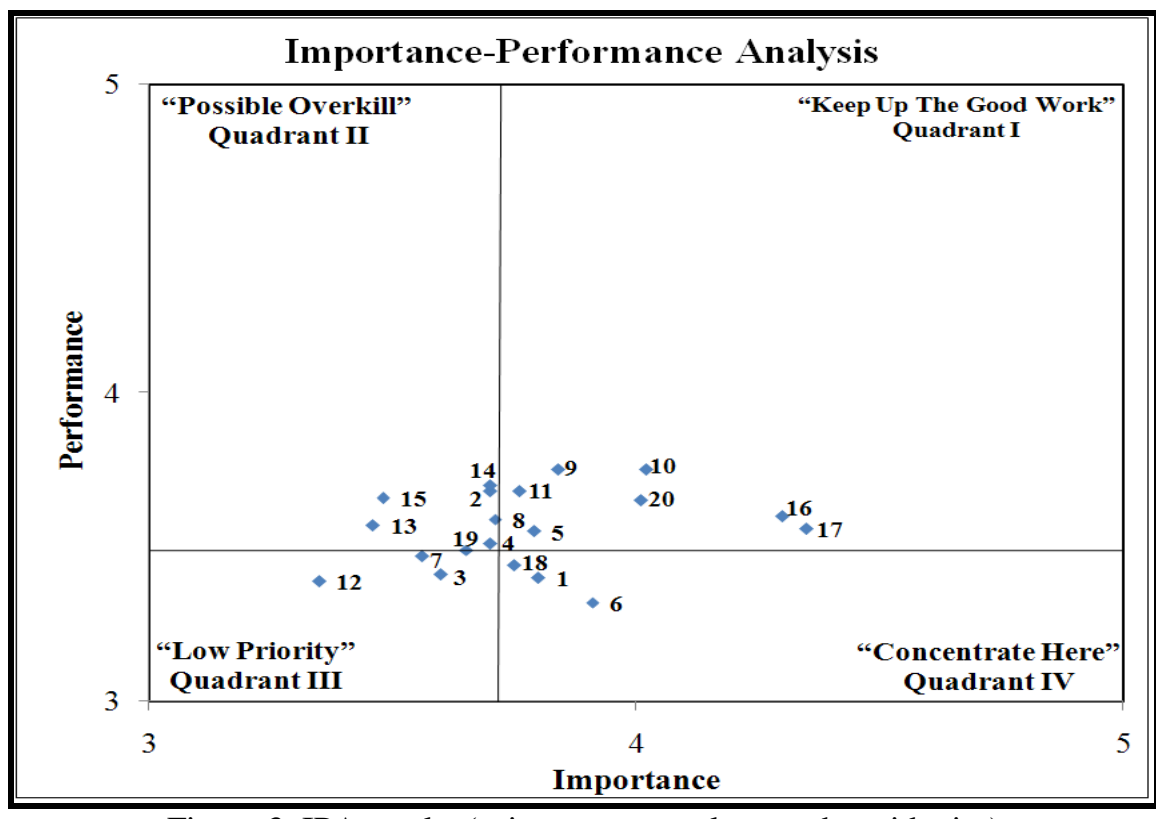

Figure 3. IPA results (using average values as the midpoint)

Table 4 shows the quadrant attributes for the various IPA items. Seven items were distributed in Quadrant I, seven in Quadrant II, three in Quadrant III, and three in Quadrant IV.

Table 4. The quadrant attributes for the various items in IPA

\begin{tabular}{cl}
\hline Quadrant & Item number* \\
\hline $\begin{array}{c}\text { Quadrant I } \\
\text { Keep Up The Good Work }\end{array}$ & $5,9,10,11,16,17$, and 20 \\
\hline $\begin{array}{c}\text { Quadrant II } \\
\text { Possible Overkill } \\
\text { Quadrant III } \\
\text { Low Priority }\end{array}$ & $2,4,8,13,14,15$, and 19 \\
\hline $\begin{array}{c}\text { Quadrant IV } \\
\text { Concentrate Here }\end{array}$ & 3,7, and 12 \\
\hline * For an explanation of the codes, please refer to Table 1. \\
\hline
\end{tabular}

\section{CONCLUSION}

Based on a SERVQUAL questionnaire developed in this study, we used the IPA method to investigate the service quality of a CDA. The overall performance of the research subject was excellent. Few of the services that were considered extremely important to the residents failed to satisfy the residents. Thus, the quality of services provided is the crucial aspect that the CDA should improve immediately. The CDA should thoroughly review the essential aspects of the various issues and develop improvement strategies to enhance residents' satisfaction.

\section{REFERENCES}

[1] C. N. Yeh, C. H. Hung, Empirical Study of Functions and Problems of Community Development Associations: The Case Study of Hsinchu City, Chung Hua Journal of Humanities and Social Sciences, 5(1), 2006, 86-118.

[2] S. T. Wang, The Resources Mobilization and Integration in Nonprofit Organization: The Study of Community Development Association, Taiwanese Journal of Social Welfare, 5(2), 2007, 103-137.

[3] T. Y. Chang, P. L. Chen, Y. H. Liu, The Relationships between Community Social Capital, Community Building and Community Development: Using Structural Equation Modeling, Kaohsiung Normal University Journal, 32(1), 2012, 24-45.

[4] C. J Li, P. T. Chen, and S. J. Chao, Region Revitalization: Use Culture as Foundation to Develop Wheat Community, Leisure Industry Research, 9(3), 2011, 46-58.

[5] M. C. Lin, On the Intermediate Group: Difficulties of Community Development in Taiwan and Its Alternative Choice, Social Policy and Social Work, 15(1), 2011, 137-166.

[6] Y. H. Tsai, Y. C. Chen, Y. L. Wang, Community Development Associations, Electoral Mobilization and Local Politics, Soochow Journal of Political Science, 25(4), 2007, 93-135. 
[7] A. Parasuraman, V. A. Zeithaml, L.L. Berry, A Conceptual Model of Service Quality and Its Implication for Future Research, Journal of Marketing, 49(4), 1985, 41-50.

[8] V. A. Zeithaml, L. L. Berry, A. Parasuraman, Communication and Control Processes in the Delivery of Service Quality, Journal of Marketing, 52(2), 1988, 35-48.

[9] A. Parasuraman, L. L. Berry, V. A. Zeithaml, Refinement and Reassessment of the SERVQUAL Scale, Journal of Retailing, 67(4), $1991,420-450$

[10] A. Parasuraman, V. A. Zeithaml, L. L. Berry, Reassessment of Expectations as a Comparison Standard in Measuring Service Quality: Implications for Further Research, Journal of Marketing, 58(1), 1994, 111-124.

[11] J. A. Martilla, J. C. James, Importance-Performance Analysis, Journal of Marketing, 41(1), 1977, 77-79.

[12] M. Hammasi, K. C. Strong, S. A. Taylor, Measuring Service Quality for Strategies Planning and Analysis in Service Firms, Journal of Applied Business Research, 10(4), 1994, 24-34.

[13] S. E Sampson, M. J. Showalter, The Performance-Importance Response Function: Observations and Implications, The Service Industries Journal, 19(1), 1999, 1-25.

[14] Shariq Hussain, Z. S. Wang, Ibrahima Kalil Toure, Abdoulaye Diop, Web Service Testing Tools: A Comparative Study, International Journal of Computer Science Issues, 10(1), 2013, 641-647.

[15] Samsudin Wahab, Nor Sabrina Norizan, The Influence of Service Recovery Strategies on Word Of Mouth: Views of Mobile Phone Users, International Journal of Computer Science Issues, 9(3), 2012, 99-108.

[16] Muhammad Aamir, Mustafa Zaidi, Husnain Mansoor, Performance Analysis of DiffServ based Quality of Service in a Multimedia Wired Network and VPN effect using OPNET, International Journal of Computer Science Issues, 9(3), 2012, 368-376.

[17] J. S. Chen, S. P. Lin, Y.H. Chan, The Development and Application of Service Quality Warning System: An Empirical Case on Taipei Songshan Airport, Journal of National Taipei College of Business, 22(1, 2012, 31-50.

[18] L. H. Yang, K. M. Ho, C. K. Chou, The Case Study of Service Quality on Technical Education in Food and Beverage Management Department-Application of Kano Model and Importance-Performance Analysis, Journal of Technological and Vocational Education, 5(1), 2012, 1-39.

[19] R. L. O’Sullivan, Marketing for Parks, Recreation, and Leisure (PA: Vemture, 1991).

[20] H. J. Chang, L. C. Liao, Applying Importance-Performance Analysis in Internal Service Quality: Case Study of an Ocean Freight Forwarder Company, Journal of Innovation and Management, 19(2), 2012, 32-53.

[21] X. Zhang, Z.P. Fan, F. Fang, W. Zheng, IPA-Based Service Quality Evaluation, Journal of Northeastern University(Natural Science), 32(4), 2011, 600-603.

[22] T. K Hsu, Y. Y. Liu, Applying Kano Model and IPA to Explore the Administrative Service Quality of Public Elementary Schools, Chung Hua Journal of Management, 12(1), 2011, 1-17.

[23] L. F. Chen, S. P. Lin, Y.C. Lin, Application of IPA and Back-Propagation Neural Network to Build a New Service Quality Decision Making Model, International Journal of Information and Management Sciences, 21(31), 2010, 91-106.

[24] W. J. Deng, Y. F. Kuo, W. C. Chen, Revised Importance-Performance Analysis: Three-Factor Theory and Benchmarking, The Service Industries Journal, 28(1), 2008, 37-51. 